\title{
Estimativa de custos de três sistemas alimentares para a recria de novilhas acasaladas aos 18 meses de idade
}

\author{
Feeding systems costs for rearing beef heifers bred at 18 months of age
}

\author{
Leonardo Canali Canellas', Pedro Rocha Marques ${ }^{2}$, Júlio Otávio Jardim Barcellos ${ }^{1,3}$, Vinícius Lampert ${ }^{1}$ \& \\ José Braccini Neto ${ }^{3}$
}

RESUMO

\begin{abstract}
A idade ao acasalamento da novilha está relacionada com a eficiência econômica da produção de bovinos. A determinação de sistemas alimentares para a recria é fundamental para que as novilhas apresentem elevada taxa de prenhez. O objetivo deste trabalho foi estimar e avaliar os custos de alternativas alimentares na recria de novilhas de corte destinadas ao acasalamento aos 18 meses de idade. Foram avaliados sistemas alimentares que atendessem o ganho de peso em cada fase da recria utilizando o campo natural e suplementos alimentares para determinar o custo final do sistema. Para tanto foram definidos os seguintes pressupostos: peso ao desmame - $160 \mathrm{~kg}$; ganho do desmame ao início do acasalamento - $140 \mathrm{~kg}$; peso ao início do acasalamento - $300 \mathrm{~kg}$ (raça britânica, $65 \%$ do peso adulto). Os tratamentos foram denominados conforme o ganho de peso diário médio (GDM) no primeiro (INV), segundo (PRI) e terceiro (VER) período, respectivamente: BAM Baixo (0,000 kg/d), Alto (1,111 kg/d) e Moderado (0,500 kg/d); MMA - Moderado (0,120 kg/d), Moderado (0,800 kg/d) e Alto $(0,500 \mathrm{~kg} / \mathrm{d}) ; \mathrm{ABB}-$ Alto $(0,373 \mathrm{~kg} / \mathrm{d})$, Baixo $(0,600 \mathrm{~kg} / \mathrm{d})$ e Baixo $(0,300 \mathrm{~kg} / \mathrm{d})$. O sistema de recria ABB apresentou o menor custo (R\$ 96,19/cab), seguido pelo MMA (R\$ 114,60/cab) e pelo BAM (R\$134,40/cab). A utilização de diferentes sistemas alimentares apresenta implicações econômicas na recria de fêmeas. Novilhas destinadas ao acasalamento aos 18 meses no outono necessitam de suplementação alimentar durante pelo menos um dos três períodos de recria. A suplementação visando obter altas taxas de ganho de peso durante o primeiro período de recria (inverno) apresentou menor custo em relação a ganhos elevados no segundo e terceiro períodos (primavera e verão, respectivamente).
\end{abstract}

Descritores: recria de novilhas, acasalamento aos 18 meses, sistemas alimentares, custo de produção, novilhas de corte.

\begin{abstract}
Age at first breeding of heifers is related with economic efficiency of cattle production. The determination of feeding systems for rearing heifers is essential to reach high pregnancy rates. The aim of this study was to estimate and evaluate the costs of feeding systems for rearing beef heifers bred at 18 months of age. Feeding systems witch enable a suitable weight gain during each rearing phase were analyzed. Native pasture and supplements were used to compose the feeding systems and to calculate the final cost of each system. Therefore, the following assumptions were defined: weaning weight $-160 \mathrm{~kg}$; weight gain from weaning to breeding $-140 \mathrm{~kg}$; weight at breeding $-300 \mathrm{~kg}$ (British breed, $65 \%$ of mature body weight). Treatments were determined according to the average daily gain (ADG) in the winter (WIN), spring (SPR) and summer (SUM) period, respectively: LHM - Low $(0.000 \mathrm{~kg} / \mathrm{d})$, High $(1.111 \mathrm{~kg} / \mathrm{d})$ e Moderate $(0.500 \mathrm{~kg} / \mathrm{d}) ; \mathrm{MMH}-$ Moderate $(0.120 \mathrm{~kg} / \mathrm{d})$, Moderate $(0.800 \mathrm{~kg} / \mathrm{d})$ and High $(0.500 \mathrm{~kg} / \mathrm{d}) ; \mathrm{HLL}-\operatorname{High}(0.373 \mathrm{~kg} / \mathrm{d})$, Low $(0.600 \mathrm{~kg} / \mathrm{d})$ and Low $(0.300 \mathrm{~kg} / \mathrm{d})$. HLL reached the lowest cost $(\mathrm{R} \$ 96,19 / \mathrm{head})$, followed by MMH (R \$ 114,60/head) and LHM ( $\$$ 134,40/head). The utilization of different feeding systems has economic involvements for rearing females. Heifers bred at 18 months in the autumn need be supplemented at least during one of the three rearing periods. Supplementing heifers to get higher weight gain during the first rearing period (winter) was cheaper than reach higher gains during the second and third periods (spring and summer, respectively).
\end{abstract}

Keywords: rearing heifers, 18-months-old breeding, feeding systems, production cost. 


\section{INTRODUÇÃO}

A idade ao acasalamento da novilha está associada à eficiência bio-econômica da pecuária de corte [6]. Em sistemas extensivos, as fêmeas são acasaladas aos três anos de idade [12], o que determina elevado percentual de fêmeas em recria, diminuindo a eficiência do sistema de produção [17].

A combinação de tecnologias permite reduzir a idade de acasalamento para 26 ou 14 meses [2]. Entretanto, no acasalamento aos 14 meses é necessário elevado aporte alimentar tanto para a recria [8] quanto para o período pós-parto da primípara aos 26 meses, aumentando os custos. Por outro lado, no acasalamento aos 26 meses o uso exclusivo do campo nativo $(\mathrm{CN})$ permite alta taxa de prenhez na novilha, porém a repetição de cria na primípara frequentemente é baixa [18].

Nesse sentido, o acasalamento aos 18 meses, no outono, é uma alternativa, pois apresenta menores custos do que o acasalamento aos 14 meses [1]. Além disso, o segundo acasalamento ocorre aos 36 meses, idade na qual a vaca já foi desmamada, permitindo a obtenção de índices de prenhez elevados [19].

Na recria da terneira até o entoure aos 18 meses são exigidos ganhos de peso moderados [5]. Independente da taxa de ganho em cada fase da recria, é possível obter taxas de prenhez superiores a $80 \%$, desde que o ganho total seja suficiente para atingir o peso mínimo (65\% do peso da vaca adulta) ao acasalamento [4].

Uma vez conhecidas as implicações biológicas do ganho de peso desmame-acasalamento é possível estabelecer sistemas alimentares que resultem nesses ganhos em cada fase da recria e quantificar os custos referentes aos mesmos [14]. O objetivo deste trabalho é estimar e avaliar os custos de diferentes sistemas alimentares para recria de novilhas acasaladas aos 18 meses de idade.

\section{MATERIAIS E MÉTODOS}

As simulações realizadas no presente trabalho se referem ao acasalamento de novilhas que nascem na primavera e são submetidas a diferentes sistemas de alimentação pós-desmame visando primeiro acasalamento aos 18 meses de idade no outono. Tendo em vista que o desmame ocorre no primeiro outono pós-nascimento, a recria da terneira consiste de três fases: inverno, primavera e verão.
A partir das três fases da recria foram projetados três sistemas de alimentação de terneiras de modo que todos resultaram no mesmo ganho total (140 kg) do desmame ao início do acasalamento aos 18 meses. Considerando um peso médio ao desmame de $160 \mathrm{~kg}$, somado ao ganho de peso pré-determinado, é possível obter um peso ao início do acasalamento de aproximadamente $300 \mathrm{~kg}$. Esse valor representa $60-65 \%$ do peso maduro de vacas de raças britânicas, e é utilizado como critério para acasalar novilhas com altas taxas de prenhez [3].

Os três sistemas de recria combinaram ganhos em cada etapa do período, sendo considerados como baixo (B), médio (M) e alto (A), dentro da fase de alimentação. Assim, um ganho considerado baixo em uma das etapas, como no inverno, por exemplo, refere-se somente a comparação com as outras duas taxas de ganho no mesmo período, ou seja, ganho moderado ou alto no inverno. Logo, é justificável que, nos sistemas de recria avaliados, o ganho de peso considerado alto no primeiro período $(0,373$ $\mathrm{kg} / \mathrm{dia}$ ), seja inferior aos ganhos considerados moderados $(0,500 \mathrm{~kg} / \mathrm{dia})$ no segundo período de outro sistema de recria.

Deste modo foram constituídos os três tratamentos, denominados sistemas de recria, conforme os ganhos pré-definidos na primeira (INV), segunda (PRI) e terceira etapa (VER) da recria, respectivamente, sendo: a primeira, dos 7 aos 12 meses de idade (outono/inverno) - 150 dias (INV); a segunda, dos 12 aos 15 meses de idade (primavera) - 90 dias (PRI) e a terceira, dos 15 aos 18 meses de idade (verão) 100 dias (VER), formando três combinações de ganhos de peso, as quais constituíram os tratamentos experimentais (Tabela 1).

Os tratamentos foram denominados de acordo com o ganho de peso diário médio (GDM) planejado na primeira, segunda e terceira etapas da recria, respectivamente: Baixo $(0,000 \mathrm{~kg} / \mathrm{d})$, Alto $(1,111 \mathrm{~kg} / \mathrm{d})$ e Moderado (0,500 kg/d) (BAM); Moderado $(0,120 \mathrm{~kg} / \mathrm{d})$, Moderado $(0,800 \mathrm{~kg} / \mathrm{d})$ e Alto $(0,500 \mathrm{~kg} / \mathrm{d})(\mathrm{MMA})$; Alto $(0,373 \mathrm{~kg} / \mathrm{d})$, Baixo $(0,600 \mathrm{~kg} / \mathrm{d})$ e Baixo $(0,300$ $\mathrm{kg} / \mathrm{d})(\mathrm{ABB})$.

As dietas foram elaboradas utilizando como base forrageira o campo natural da região da Campanha do Rio Grande do Sul e as suas variações com a introdução de espécies forrageiras cultivadas de inverno ou de verão. A composição botânica do campo natural compreende basicamente os gêneros Pani- 
cum e Paspalum, com 8,0\% de PB e 58\% de NDT no outono/inverno, $13,2 \%$ de PB e $64 \%$ de NDT e 10,0\% de PB e $61 \%$ de NDT na primavera e verão, respectivamente [7].

$\mathrm{O}$ alimento volumoso predominante nos três sistemas de recria foi constituído pelo campo natural. Porém, no sistema ABB além do campo natural foi utilizada a opção de pastagem cultivada de aveia preta (Avena strigosa) consorciada com azevém (Lolium multiflorum) na primeira fase (INV). O custo total por hectare da pastagem cultivada de inverno foi de $\mathrm{R} \$ 345,00$, considerando uma lotação de 1,56 UA/ha (1 UA= $450 \mathrm{~kg}$ ), representando 3,5 terneiras/ha pesando em média $200 \mathrm{~kg}$ em pastejo durante 150 dias. Já nos sistemas BAM e MMA, durante a segunda fase (PRI), foi considerada a utilização do campo nativo melhorado com trevo branco (Trifolium repens) e cornichão (Lotus corniculatus) cujo custo por hectare foi de $\mathrm{R} \$ 640,00$, permitindo uma lotação de 2,0 $\mathrm{UA} /$ ha com aproveitamento de oito meses ao ano. Isto representa uma lotação de aproximadamente 4,0 terneiras/ha durante o período, totalizando um custo médio de R \$60,00/cab. Na composição do suplemento protéico/energético foram utilizados produtos disponíveis no mercado regional do Rio Grande do Sul cujas características de mercado, logís-ticas e nutricionais eram factíveis para o uso (Tabela 2).

Tabela 1. Sistemas de recria (Moderado, Moderado, Alto - MMA; Baixo, Alto, Moderado - BAM; Alto, Baixo, Baixo - ABB) de novilhas de corte para o acasalamento aos 18 meses: Ganho de peso diário médio (GDM), duração da fase de recria (Dias) e ganho de peso total (GPT).

\begin{tabular}{|c|c|c|c|c|c|c|c|c|c|c|c|c|}
\hline \multirow{4}{*}{$\begin{array}{l}\text { Sistema } \\
\text { de R ecria }\end{array}$} & \multicolumn{12}{|c|}{ Fases da R ecria } \\
\hline & \multicolumn{3}{|c|}{$\begin{array}{c}\text { Inverno } \\
\text { (7-12 meses) }\end{array}$} & \multicolumn{3}{|c|}{$\begin{array}{c}\text { Primavera } \\
(12-15 \text { meses })\end{array}$} & \multicolumn{3}{|c|}{$\begin{array}{c}\text { Verão } \\
\text { (15-18 meses) }\end{array}$} & \multicolumn{3}{|c|}{ Total } \\
\hline & \multirow{2}{*}{ Dias } & GDM & GPT & \multirow{2}{*}{ Dias } & GDM & GPT & \multirow{2}{*}{ Dias } & GDM & GPT & \multirow{2}{*}{ Dias } & GDM & GPT \\
\hline & & $\mathrm{kg}$ & $\mathrm{kg}$ & & $\mathrm{kg}$ & $\mathrm{kg}$ & & $\mathrm{kg}$ & $\mathrm{kg}$ & & $\mathrm{kg}$ & $\mathrm{kg}$ \\
\hline BAM & 150 & 0,000 & 0,00 & 90 & 1,111 & 100,0 & 100 & 0,400 & 40,0 & 340 & 0,412 & 140 \\
\hline MMA & 150 & 0,120 & 18,0 & 90 & 0,800 & 72,0 & 100 & 0,500 & 50,0 & 340 & 0,412 & 140 \\
\hline $\mathrm{ABB}$ & 150 & 0,373 & 56,0 & 90 & 0,600 & 54,0 & 100 & 0,300 & 30,0 & 340 & 0,412 & 140 \\
\hline
\end{tabular}

Tabela 2. Alimentos concentrados utilizados nos sistemas alimentares com seus respectivos valores de proteína bruta (PB) e nutrientes digestíveis totais (NDT) na matéria seca (MS) e seus custos (R\$).

\begin{tabular}{cccc}
\hline Produto & \%PB $(\mathbf{M S})^{*}$ & \%NDT $(\mathbf{M S})^{*}$ & Custo R $\mathbf{\text { /kg**}}^{* *}$ \\
\hline Casca de Soja & 15,0 & 80,0 & 0,38 \\
Farelo de Arroz & 10,0 & 88,0 & 0,30 \\
Farelo de Soja & 44,0 & 84,0 & 0,90 \\
Farelo de Trigo & 13,0 & 85,0 & 0,29 \\
Milho & 9,50 & 88,0 & 0,36 \\
Ração Comercial (16\% PB) & 16,0 & 80,0 & 0,60 \\
Sorgo em grão & 13,6 & 76,0 & 0,29 \\
Sal Proteinado & 45,0 & -- & 1,15 \\
Farelo de Algodão & 38,0 & 75,0 & 0,73 \\
\hline
\end{tabular}

Fonte: *NRC, 1996; **Preços médios de mercado no RS em julho de 2009. 
Os cálculos das dietas foram realizados por meio de um software [13] de acordo com as exigências nutricionais de proteína bruta e energia metabolizável para mantença e ganho de peso, considerando o peso médio dos animais em cada período do sistema. Após a análise dos resultados, os alimentos que promoveram os ganhos de peso pré-estabelecidos foram utilizados na composição do sistema alimentar para a análise do custo da dieta, contabilizando somente os valores desembolsados referentes à suplementação, pastagens cultivadas ou campo nativo melhorado, uma vez que os demais custos podem ser considerados como constantes entre os diferentes sistemas, variando somente os custos referentes à alimentação.

Além desses valores foi incluído o custo de oportunidade do campo nativo o qual corresponde a $40 \mathrm{~kg}$ de boi gordo ao ano, totalizando, em média, $\mathrm{R} \$$ 105,00/ha/ano. A carga animal média nessa área de campo nativo equivale a $300 \mathrm{~kg}$ de peso vivo por hectare. Portanto, em todos os sistemas foi considerado este custo e a ele adicionados os valores referentes a cada alternativa de alimentação complementar para atingir o ganho pré-determinado, sendo, no entanto, apresentados somente para os sistemas alimentares de menor custo em cada sistema de recria (Tabela 6).

Na simulação o alimento que atendeu as exigências para o ganho definido e que apresentou o menor custo dentro do período INV, PRI ou VER cons- tituiu o sistema alimentar de determinado modelo de ganho de peso do sistema de recria. Os custos dos alimentos, dos insumos e gastos com confecção das pastagens bem como do custo de oportunidade utilizados nesta simulação foram obtidos a partir de preços médios de mercado vigentes no Rio Grande do Sul, referentes ao mês de julho de 2009. Cabe ressaltar que o objetivo do trabalho é demonstrar alternativas alimentares e que os custos podem variar conforme a região, logística, volume adquirido de suplementos, insumos e conjuntura do mercado. Além disso, os valores considerados foram médios, havendo variação entre fornecedores.

\section{RESULTADOS}

As Tabelas 3, 4 e 5 demonstram os sistemas alimentares e os seus respectivos custos. Na Tabela 6 pode ser visualizado o custo final por novilha em cada sistema alimentar (BAM, MMA e ABB).

No sistema de recria BAM (Tabela 3 ) o custo total por novilha foi de $\mathrm{R} \$ 134,40$ (Tabela 6), o mais alto dentre os três modelos propostos. $\mathrm{O}$ farelo de soja, fornecido a $0,3 \%$ do peso vivo, foi o alimento utilizado na primavera para complementar a dieta, por apresentar o menor custo dentre as alternativas alimentares existentes.

No sistema alimentar MMA (Tabela 4) o custo totalizou $\mathrm{R} \$ 114,60 / \mathrm{cab}$ (Tabela 6), inferior ao sistema BAM e superior ao sistema ABB. Este sistema alimentar é bastante semelhante ao sistema anterior,

Tabela 3. Custos de sistemas alimentares para novilhas de corte no sistema de recria: Baixo (INV), Alto (PRI) e Moderado (VER) (BAM).

\begin{tabular}{|c|c|c|c|c|c|}
\hline INV & \multirow{2}{*}{$\begin{array}{c}\text { Custo* } \\
\text { (R\$) }\end{array}$} & PRI & \multirow{2}{*}{$\begin{array}{c}\text { Custo } \\
(\mathbf{R} \$)\end{array}$} & VER & \multirow{2}{*}{$\begin{array}{c}\text { Custo: } \\
\text { (R\$) }\end{array}$} \\
\hline $\begin{array}{c}\text { Sistema } \\
\text { Alimentar } \\
\text { GDM 0,000 }\end{array}$ & & $\begin{array}{c}\text { Sistema } \\
\text { Alimentar GDM } \\
\mathbf{1 , 1 1 1}\end{array}$ & & $\begin{array}{c}\text { Sistema } \\
\text { Alimentar } \\
\text { GDM 0,400 }\end{array}$ & \\
\hline Campo Nativo & -- & $\begin{array}{c}\text { Farelo de Soja } \\
0,3 \% \\
\text { PV } 220 * *\end{array}$ & 59,40 & Campo Nativo & -- \\
\hline Campo Nativo & -- & $\begin{array}{c}\text { Campo Nativo } \\
\text { melhorado }\end{array}$ & 60,00 & Campo Nativo & -- \\
\hline Campo Nativo & -- & $\begin{array}{c}\text { Ração Comercial } \\
1,4 \% \text { PV }\end{array}$ & 189,00 & Campo Nativo & -- \\
\hline Campo Nativo & -- & $\begin{array}{c}\text { Farelo de Algodão } \\
0,5 \% \mathrm{PV}\end{array}$ & 80,30 & Campo Nativo & -- \\
\hline
\end{tabular}

*Custo R \$ 105,00/ano está demonstrado no resultado final (Tabela 6)

**Peso médio das fêmeas no período 
pois apresenta também um GDM elevado no período PRI, no entanto, um pouco inferior $(0,800 \mathrm{~kg} / \mathrm{d})$.

O modelo ABB (Tabela 5) apresentou o menor custo $\mathrm{R} \$$ 96,19/cab (Tabela 6) dentre os sistemas de recria. Neste modelo os ganhos de peso nos três períodos da recria são mais homogêneos entre si do que nos demais tratamentos. $\mathrm{O}$ sistema não utiliza suplementação no período de primavera como nos sistemas anteriores, mas sim no período inverno. A alternativa alimentar de menor custo no período de INV foi o farelo de trigo a $0,2 \%$ do PV com adição de $15 \mathrm{~g}$ de ureia.

\section{DISCUSSÃO}

Na composição dos custos dos sistemas alimentares foi utilizada a alternativa alimentar de menor custo, desde que fossem atendidas as exigências nutricionais para o ganho de peso desejado. Para a mesma taxa de prenhez, o custo alimentar pode ser bastante distinto [16], sendo necessária uma análise criteriosa dos diferentes recursos disponíveis no sistema de produção e definindo quais deverão ser destinados a recria das fêmeas.

Os períodos durante a recria não têm a mesma duração e, além disso, cada um apresenta particularidades como o estádio qualitativo e quantitativo da pastagem nativa e a disponibilidade dos alimentos suplementares, o que pode afetar o tipo de dieta e os custos de cada sistema. Desse modo, cada período de recria possui diferentes alternativas alimentares [4].

O sistema de recria BAM (Tabela 3) apresentou o maior custo por novilha dentre os modelos propostos (Tabela 6). Esse sistema baseia-se em manutenção de peso no inverno e GDM moderado no verão, havendo necessidade de elevada taxa de ganho de peso $(1,111 \mathrm{~kg} / \mathrm{dia})$ no período intermediário, representado pela primavera. Mesmo por meio da ex-

Tabela 4. Custos de sistemas alimentares para novilhas de corte no sistema de recria: Moderado (INV), Moderado (PRI) e Alto (VER) (MMA).

\begin{tabular}{|c|c|c|c|c|c|}
\hline INV & \multirow{2}{*}{$\begin{array}{c}\text { Custo* }^{*} \\
\text { (R) }\end{array}$} & PRI & \multirow{2}{*}{$\begin{array}{c}\text { Custo } \\
\text { (R\$) }\end{array}$} & VER & \multirow{2}{*}{$\begin{array}{c}\text { Custo: } \\
\text { (R\$) }\end{array}$} \\
\hline $\begin{array}{c}\text { Sistema } \\
\text { Alimentar } \\
\text { GDM 0,120 }\end{array}$ & & $\begin{array}{c}\text { Sistema } \\
\text { Alimentar GDM } \\
\mathbf{0 , 8 0 0}\end{array}$ & & $\begin{array}{c}\text { Sistema } \\
\text { Alimentar } \\
\text { GDM 0,500 }\end{array}$ & \\
\hline Campo Nativo & -- & $\begin{array}{c}\text { Farelo de Soja } \\
0,2 \% \text { PV }(220)^{* *}\end{array}$ & 39,60 & Campo Nativo & -- \\
\hline Campo Nativo & -- & $\begin{array}{l}\text { Campo Nativo } \\
\text { melhorado }\end{array}$ & 60,00 & Campo Nativo & -- \\
\hline Campo Nativo & -- & $\begin{array}{c}\text { Ração Comercial } \\
1,2 \% \text { PV }\end{array}$ & 162,0 & Campo Nativo & -- \\
\hline Campo Nativo & -- & $\begin{array}{c}\text { Farelo de Trigo } \\
0,7 \% \\
\mathrm{PV}+\text { ureia }(15 \mathrm{~g})\end{array}$ & 46,15 & Campo Nativo & -- \\
\hline Campo Nativo & -- & $\begin{array}{c}\text { Farelo de Arroz } \\
0,7 \% \\
\mathrm{PV}+\text { ureia }(15 \mathrm{~g})\end{array}$ & 47,19 & Campo Nativo & -- \\
\hline Campo Nativo & -- & $\begin{array}{c}\text { Casca de Soja } \\
0,7 \% \text { PV }\end{array}$ & 59,85 & Campo Nativo & -- \\
\hline Campo Nativo & -- & $\begin{array}{c}\text { Milho } 0,5 \% \\
\text { PV + ureia }(15 \mathrm{~g})\end{array}$ & 41,49 & Campo Nativo & -- \\
\hline Campo Nativo & -- & $\begin{array}{c}\text { Farelo de Algodão } \\
0,4 \% \text { PV }\end{array}$ & 64,24 & Campo Nativo & -- \\
\hline
\end{tabular}

*Custo R \$ 105,00/ano está demonstrado no resultado final (Tabela 6).

**Peso médio das fêmeas no período. 
ploração do crescimento compensatório durante o período no qual o campo nativo apresenta melhor qualidade, o uso exclusivo da pastagem natural durante a primavera não contém energia suficiente para ganhos de peso dessa magnitude. Por isso, o modelo propõe que a dieta seja complementada por outros alimentos. Nesse caso, o farelo de soja, fornecido a $0,3 \%$ do peso vivo, foi o alimento que apresentou o menor custo.

A utilização de pastagens cultivadas ou melhoradas representa uma alternativa para assegurar adequada taxa de crescimento e sucesso reprodutivo em novilhas de corte [11]. Nesse sentido, outro recurso alimentar que poderia ser utilizado durante a primavera no sistema BAM é o campo nativo melhorado pela introdução de trevo-branco e cornichão, tendo apresentado praticamente o mesmo custo/cabeça comparado ao farelo de soja.

A opção pelo uso da pastagem em detrimento do farelo de soja depende também da região em que se insere a propriedade. Em regiões que não produzem soja a utilização do farelo tende a apresentar maior custo devido ao valor pago pelo frete do produto. Por outro lado, a implantação desse tipo de pastagem requer um desembolso superior, visto que o período de utilização da mesma (oito meses) supera o período de recria "PRI" (três meses). Com isso o gasto imediato é maior, sendo indicada a diluição do custo por meio da utilização da pastagem por outras categorias animais, o que pode tornar inviável a utilização do campo nativo melhorado dependendo do sistema de produção.

Além do alto custo, o sistema BAM apresenta elevado risco, tendo em vista que consiste na manutenção das terneiras exclusivamente em campo nativo durante o período nutricional mais crítico do ano. Isso ocorre porque, dependendo das condições climáticas (secas, inverno rigoroso etc.), pode haver perda de peso dos animais, o que é contra-indicado para terneiras antes da puberdade. O comprometi-

Tabela 5. Custos de sistemas alimentares para novilhas de corte no sistema de recria: Alto (INV), Baixo (PRI) e Baixo (VER) (ABB).

\begin{tabular}{|c|c|c|c|c|c|}
\hline INV & \multirow{2}{*}{$\begin{array}{c}\text { Custo } \\
(\mathbf{R} \$)\end{array}$} & PRI & \multirow{2}{*}{$\begin{array}{c}\text { Custo* } \\
(\mathbf{R} \$)\end{array}$} & VER & \multirow{2}{*}{$\begin{array}{c}\text { Custo* } \\
\text { (R\$) }\end{array}$} \\
\hline $\begin{array}{l}\text { Sistema Alimentar } \\
\text { GDM } \mathbf{0 , 3 7 3}\end{array}$ & & $\begin{array}{c}\text { Sistema } \\
\text { Alimentar } \\
\text { GDM 0,600 }\end{array}$ & & $\begin{array}{c}\text { Sistema } \\
\text { Alimentar } \\
\text { GDM 0,300 }\end{array}$ & \\
\hline $\begin{array}{c}\text { Farelo de Arroz 0,2\% } \\
\text { PV }(200 \mathrm{~kg})^{* *}+\text { Ureia } \\
(15 \mathrm{~g})\end{array}$ & 21,64 & Campo Nativo & -- & Campo Nativo & -- \\
\hline $\begin{array}{c}\text { Farelo de Soja } \\
\text { 0,2\% PV }\end{array}$ & 60,00 & Campo Nativo & -- & Campo Nativo & -- \\
\hline $\begin{array}{c}\text { Farelo de Trigo 0,2\% } \\
\text { PV + Ureia }(15 \mathrm{~g})\end{array}$ & 21,19 & Campo Nativo & -- & Campo Nativo & -- \\
\hline $\begin{array}{c}\text { Casca de Soja } 0,2 \% \\
\text { PV + Ureia }(15 \mathrm{~g})\end{array}$ & 27,55 & Campo Nativo & -- & Campo Nativo & -- \\
\hline $\begin{array}{c}\text { Milho 0,4\% } \\
\text { PV + Ureia (15 g) }\end{array}$ & 55,64 & Campo Nativo & -- & Campo Nativo & -- \\
\hline $\begin{array}{l}\text { Pastagem hibernal } \\
\text { Maio-Outubro }\end{array}$ & 98,57 & Campo Nativo & -- & Campo Nativo & -- \\
\hline $\begin{array}{c}\text { Ração Comercial } \\
0,5 \% \mathrm{PV}\end{array}$ & 102,27 & Campo Nativo & -- & Campo Nativo & -- \\
\hline $\begin{array}{l}\text { Sal Proteínado } \\
\text { 0,2\% PV }\end{array}$ & 69,00 & Campo Nativo & -- & Campo Nativo & -- \\
\hline $\begin{array}{l}\text { Sorgo } 0,4 \% \mathrm{PV}+ \\
\quad \text { Ureia }(15 \mathrm{~g})\end{array}$ & 41,64 & Campo Nativo & -- & Campo Nativo & -- \\
\hline
\end{tabular}

*Custo R\$ 105,00/ano está demonstrado no resultado final (Tabela 6)

**Peso médio das fêmeas no período 
mento parcial no desenvolvimento de novilhas durante a primeira fase pós-desmame pode ser irreversível e comprometer o desempenho reprodutivo no acasalamento aos 18 meses [5]. A perda de peso no inverno acarretaria em menores pesos nos períodos posteriores, inclusive ao início do acasalamento aos 18 meses, com possível inviabilização do sistema.

O sistema alimentar MMA (Tabela 4) apresentou custo intermediário entre os três sistemas (Tabela 6), sendo inferior ao sistema BAM e superior ao sistema ABB. A menor necessidade de GDM na primavera $(0,311 \mathrm{~kg} / \mathrm{dia}$ a menos) em relação ao sistema BAM, se torna expressiva no cálculo da quantidade de suplemento a ser utilizado (0,3\% PV vs $0,2 \%$ PV respectivamente para BAM e MMA), oportunizando uma redução nos custos. Neste sistema o farelo de soja também foi o alimento de menor custo. Entretanto, a combinação de milho com ureia (15 $\mathrm{g} / \mathrm{cab} / \mathrm{dia}$ ) apresentou custo semelhante, podendo apresentar competitividade conforme a região e o comportamento dos preços de mercado.
Os ganhos de peso no sistema MMA foram distribuídos mais uniformemente entre os períodos do que no sistema anterior, tendo em vista que o ganho compensatório no sistema BAM tende a ser maior, devido à restrição alimentar mais intensa. Cabe ressaltar que nesse sistema as fêmeas seriam mantidas em campo nativo, assim como as novilhas do sistema BAM, porém no MMA a lotação em campo nativo proposta é menor, oportunizando melhor desempenho durante a primeira fase (INV). Essa situação também pode representar um risco, devido à dependência exclusiva do campo natural, podendo ocasionar prejuízos no desempenho reprodutivo, como discutido anteriormente.

O modelo ABB (Tabela 5) apresentou o menor custo (Tabela 6) dentre os sistemas de recria. Neste modelo os ganhos de peso nos três períodos da recria são mais homogêneos entre si do que nos demais tratamentos. O sistema não utiliza suplementação no período de primavera como nos sistemas anteriores, mas sim no período inverno. Nesse mo-

Tabela 6. Sistemas alimentares de menor custo para novilhas de corte conforme o sistema de recria para o acasalamento aos 18 meses: (Moderado, Moderado, Alto - MMA; Baixo, Alto, Moderado - BAM; Alto, Baixo, Baixo - ABB).

\begin{tabular}{|c|c|c|c|c|c|}
\hline $\begin{array}{l}\text { Sistema de } \\
\text { Recria }\end{array}$ & $\begin{array}{c}\text { Fase de } \\
\text { recria }\end{array}$ & $\begin{array}{c}\text { Sistema } \\
\text { Alimentar }\end{array}$ & $\begin{array}{c}\text { Custo } \\
\text { (R\$) }\end{array}$ & $\begin{array}{c}\text { Custo } \\
\text { Campo } \\
\text { Nativo/Ano } \\
(\mathbf{R} \$)\end{array}$ & $\begin{array}{l}\text { Custo } \\
\text { Total } \\
(\mathbf{R} \$)\end{array}$ \\
\hline \multirow{4}{*}{$\mathrm{ABB}$} & INV & $\begin{array}{c}\text { Farelo de Trigo } \\
0,2 \% \mathrm{PV}+ \\
\text { Ureia }\end{array}$ & 21,19 & & \\
\hline & PRI & Campo Nativo & -- & & \\
\hline & VER & Campo Nativo & -- & & \\
\hline & TOTAL & & 21,19 & 75,00 & 96,19 \\
\hline \multirow{4}{*}{ MMA } & INV & Campo Nativo & -- & & \\
\hline & PRI & $\begin{array}{c}\text { Farelo de Soja } \\
\text { 0,2\% PV }\end{array}$ & 39,60 & & \\
\hline & VER & Campo Nativo & -- & & \\
\hline & TOTAL & & 39,60 & 75,00 & 114,60 \\
\hline \multirow{4}{*}{ BAM } & INV & Campo Nativo & & & \\
\hline & PRI & $\begin{array}{c}\text { Farelo de Soja } \\
\text { 0,3\% PV }\end{array}$ & 59,40 & & \\
\hline & VER & Campo Nativo & -- & & \\
\hline & TOTAL & & 59,40 & 75,00 & 134,40 \\
\hline
\end{tabular}


mento as terneiras são mais leves, exigindo menor quantidade de suplementação. Posteriormente, ganhos de peso equilibrados durante a primavera e o verão permitem à novilha alcançar o peso pré-determinado por ocasião do acasalamento.

A alternativa alimentar de menor custo no período de INV foi o farelo de trigo com ureia. No entanto o farelo de arroz com ureia apresentou custo muito semelhante, podendo, em determinadas regiões, apresentar maior competitividade. Observa-se que o custo da pastagem hibernal (aveia/azevém) foi bem superior ao uso dos suplementos descritos anteriormente. Isso ocorreu porque os custos de confecção desse tipo de pastagem (adubação, sementes, plan-tio) são elevados. Entretanto, em sistemas de produção que integram lavoura e pecuária, a utilização de pastagens de crescimento hibernal tende a apresentar custo reduzido, devido ao aproveitamento de recursos como maquinário e mão-de-obra por parte da pecuária [10]. A utilização de pastagens de estação fria para melhorar o desempenho de fêmeas bovinas de corte em recria é prática usual no Estado do Rio Grande do Sul [15]. Por isso, dependendo das características da propriedade, a pastagem de aveia/azevém pode representar uma alternativa economicamente viável.

Nos sistemas simulados, a suplementação foi utilizada somente em um dos três períodos de recria, sendo o campo nativo o principal recurso alimentar utilizado. Entretanto, este muitas vezes não atende as exigências nutricionais para os ganhos de peso desejados. Baseado nisso, o uso estratégico de suplementos acelera o crescimento de fêmeas no período pós-desmama [9]. Os resultados do presente trabalho demonstram que a complementação da dieta em animais mais jovens e com menor peso vivo tende a apresentar maior viabilidade econômica, além de trazer vantagens no desenvolvimento adequado das terneiras durante o estágio inicial de desenvolvimento.

Outro aspecto que deve ser ressaltado é que na composição do custo final do sistema de recria o custo de oportunidade da terra teve grande participação para a formação dos custos, devido à base alimentar ter sido constituída pelo campo nativo. Vale destacar que este custo muitas vezes não é contabilizado nas propriedades devido ao fato de não gerar desembolso, o que erroneamente pode induzir a uma diminuição do custo de recria.

A participação do campo nativo deve sempre ser a maior possível, pois diminui a necessidade de desembolso com suplementos. Por outro lado, a suplementação serve de auxílio para atingir determinados objetivos dentro do sistema de produção [15]. Contudo, a utilização de concentrados na suplementação da dieta de bovinos concorre com outras áreas de produção animal, como a cadeia produtiva de aves e suínos. Esse fato pode tornar antieconômica a utilização de alguns suplementos, devido a sua concorrência dentro do setor em determinadas épocas.

O conhecimento da nutrição é de extrema importância uma vez que alguns alimentos podem ser substituídos por outros que atendam às mesmas exigências nutricionais, cumprindo com os objetivos de produção. A decisão deve sempre convergir para a opção de menor custo. Utilizar alimentos produzidos na região normalmente reduz os custos, principalmente devido à diminuição dos gastos com frete. No entanto, é necessário o conhecimento não só das exigências nutricionais dos animais, mas também das estratégias para a construção de um sistema alimentar efetivo [16].

Com base neste estudo são demonstrados os três sistemas de criação da novilha a partir do desmame até o acasalamento aos 18 meses (Figura 1). Em todos os sistemas a base é o campo nativo e, conforme a região fisiográfica, suplementos alimentares ou pastagens cultivadas devem ser incluídos.

\section{CONCLUSÕES}

A utilização de diferentes sistemas alimentares influencia no custo de recria de novilhas acasaladas aos 18 meses. Novilhas destinadas ao acasalamento aos 18 meses no outono necessitam de suplementação alimentar durante pelo menos um dos três períodos de recria. A suplementação visando obter altas taxas de ganho de peso durante o primeiro período de recria apresentou menor custo do que no segundo e terceiro períodos. 
Figura 1. Síntese dos sistemas de recria mais indicados para cada região do Rio Grande do Sul com base no campo nativo (CN), suplementos e pastagens cultivadas.

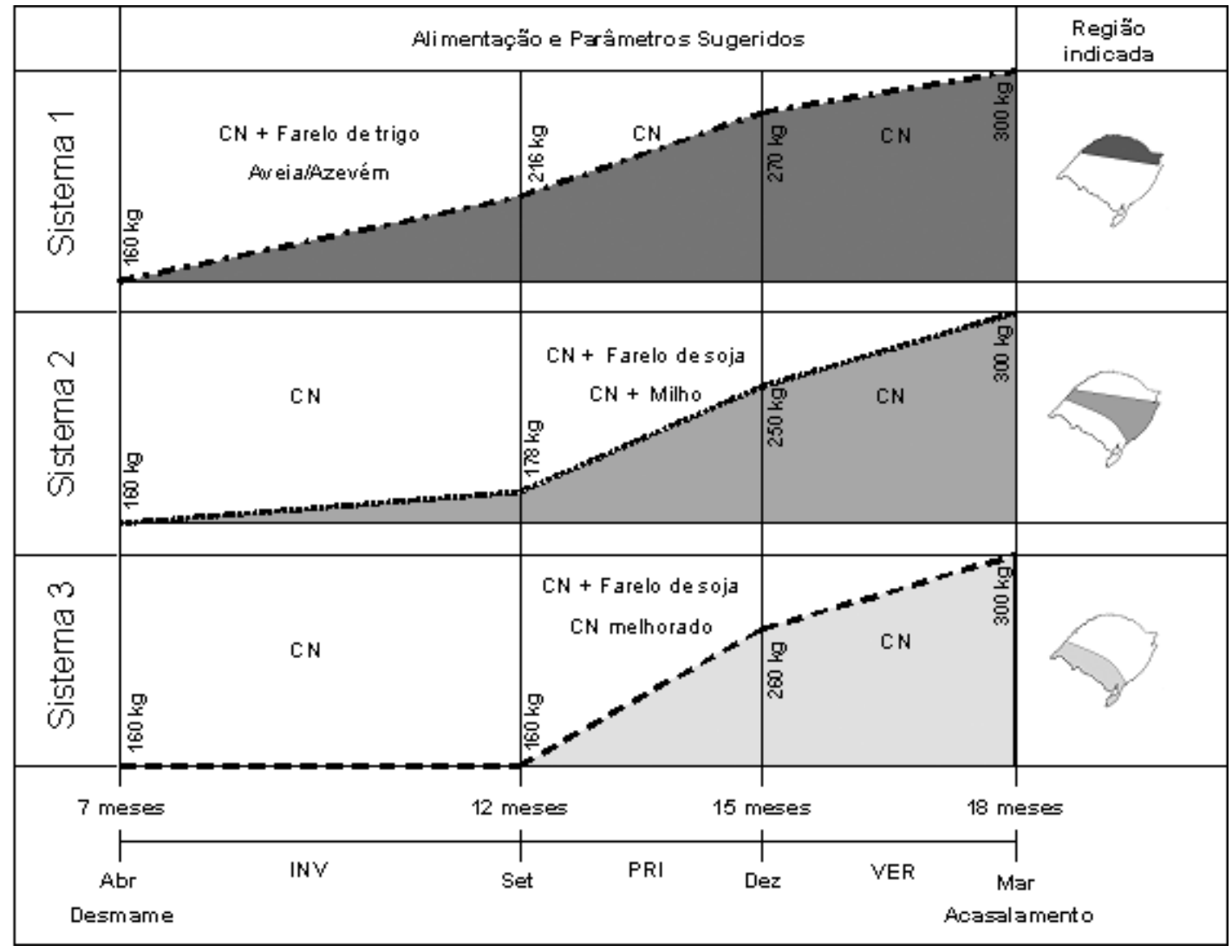

\section{REFERÊNCIAS}

1 Barcellos J.O.J., Prates E.R. \& Silva M.D. 2002. Manejo da novilha de corte e a idade à puberdade. In: Anais do VII Ciclo de Palestras em Produção e Manejo de Bovinos, 2002. Canoas. Universidade Luterana do Brasil. pp. 95-126.

2 Beretta V. \& Lobato J.F.P. 1996. Efeitos da ordem da utilização de pastagens melhoradas do ganho de peso e desempenho reprodutivo de novilhas de corte. Revista Brasileira de Zootecnia. 25: 46-57.

3 Bolze R. \& Corah L.R. 1993. Selection and development of replacement heifers. Manhattan: Kansas State University Cooperative. Extension Service, 10p.

4 Costa E.C., Barcellos J.O.J., Peripolli V., Oliveira T.E., López J. \& Bracini Neto J. 2009. Crescimento de novilhas de corte com diferentes ganhos de peso dos 12 aos 18 meses de idade. Acta Scientiae Veterinariae. 37: 125-132.

5 Di Marco O.N., Barcellos J.O.J. \& Costa E.C. 2007. Crescimento de bovinos de corte. Porto Alegre: Universidade Federal do Rio Grande do Sul, 248p.

6 Figueiredo D.M., Paulino M.F., Detmann E., Souza M.G. Couto V.R. \& Sales M.F.L. 2008. Estratégias de suplementação para antecipação da idade à puberdade para novilhas de corte em pastagem tropical. Acta Scientiarum Animal Sciences. 30: 415-423.

7 Freitas E.A., Lopez J. \& Prates E.R. 1976. Produtividade de matéria seca, proteína digestível e nutrientes digestíveis totais em pastagem nativa do Rio Grande do Sul. Anuário Técnico IPZFO. 3: 454-515.

8 Freitas S.G. \& Lobato J.F.P. 2003. Desempenho reprodutivo e produtivo de novilhas de corte aos dois anos de idade submetidas a diferentes alternativas de alimentação. In: Anais da Reunião Anual da Sociedade Brasileira de Zootecnia, 2003. Santa Maria: SBZ, 2003. CD-ROM.

9 Frizzo A., Rocha M.G. \& Restle J. 2003. Produção de forragem e retorno econômico da pastagem de aveia e azevém sob pastejo com bezerras de corte submetidas a níveis de suplementação energética. Revista Brasileira de Zootecnia. 32: 632642. 
10 Lopes M.L.T., Carvalho P.C.F., Anghinoni I., Santos D., Kuss F., Freitas F.K. \& Flores J.P.C. 2008. Sistema de integração lavoura-pecuária: desempenho e qualidade da carcaça de novilhos superprecoces terminados em pastagem de aveia e azevém manejada sob diferentes alturas. Ciência Rural. 38: 178-184

11 Menegaz A.L., Lobato J.F.P. \& Pereira A.C.G. 2008. Influência do manejo alimentar no ganho de peso e no desempenho reprodutivo de novilhas de corte. Revista Brasileira de Zootecnia. 37: 1844-1852.

12 Nabinger C., Sanguiné E., Mielitz Netto C.G.A., Waquil P.D., Miguel L.A. \& Schneider S. 2005. Diagnóstico de sistemas de produção de bovinocultura de corte do Estado do Rio Grande do Sul: Relatório. Porto Alegre: UFRGS. 265 p.

13 National Research Council (NRC). 1996. Nutrient requirements of beef cattle. 6th edn. Washington: D.C. National Academy Press, 242 p.

14 Oaigen R.P., Barcellos J.O.J., Christofari L.F., Bracini Neto J., Oliveira T.E. \& Prates E.R. 2008. Melhoria organizacional na produção de bezerros de corte a partir dos centros de custos. Revista Brasileira de Zootecnia. 37: $580-587$.

15 Pötter L., Rocha M.G., SouzaA.N.M., Roso D., Glienke C.L., Costa V.G., Oliveira Neto R.A. \& Ilha G.F. 2009. Desenvolvimento de novilhas de corte sob alternativas de mineralização em pastagem de azevém. Ciência Rural. 39: 182-187.

16 Rocha M.G. \& Lobato J.F.P. 2002. Avaliação do desempenho reprodutivo de novilhas de corte primíparas aos dois anos de idade. Revista Brasileira de Zootecnia. 31: 1388-1395.

17 Roso D., Rocha M.G., Pötter L., Glienke C.L., Costa V.G. \& Ilha G.F. 2009. Recria de bezerras de corte em alternativas de uso da pastagem de azevém. Revista Brasileira de Zootecnia. 38: 240-248.

18 Rovira J. 1996. Manejo nutritivo de los rodeos de cria em pastoreo. Uruguay: Ed. Hemisfério Sur Montevideo, 288p.

19 Sampedro D., Vogel O. \& Celser R. 1995. Alternativas de manejo para entorar la vaquilla a los 18 meses de edad: su influencia sobre el porcentaje de $2^{\circ}$ entore y prenhez. Mercedes: INTA. 9p. (Circular Técnica). 